\title{
Relationship between Physical Properties and Preparation Atmosphere of Manganese-doped $\mathrm{ZnO}-\mathrm{P}_{2} \mathrm{O}_{5}$ Glasses
}

\author{
Hirokazu Masai, ${ }^{1}$ Toshiaki Ina, ${ }^{2}$ Hiromi Kimura, ${ }^{3}$ \\ Noriaki Kawaguchi, ${ }^{3}$ and Takayuki Yanagida ${ }^{3}$ \\ ${ }^{1}$ National Institute of Advanced Industrial Science and Technology, \\ 1-8-31 Midorigaoka, Ikeda, Osaka 563-8577, Japan \\ ${ }^{2}$ Japan Synchrotron Radiation Research Institute (JASRI/SPring-8), Kouto, Sayo-cho, Hyogo 679-5198, Japan \\ ${ }^{3}$ Nara Institute of Science and Technology, 8916-5 Takayama-cho, Ikoma, Nara 630-0192, Japan
}

(Received January 31, 2021; accepted May 25, 2021)

Keywords: glass, luminescence, manganese, XAFS, scintillation

Manganese-doped zinc phosphate (MnZP) glasses were prepared in Ar and air to examine the relationship between the physical properties and preparation atmosphere. The glass transition temperatures of these MnZP glasses were almost the same regardless of the preparation atmosphere. Although the absorption spectra of the $15 \mathrm{~mol} \%$-doped MnZP glasses prepared in different atmospheres exhibited significant differences, only small differences in the absorption tail were observed in the other MnZP glasses with lower Mn concentrations. It was found that the Mn K-edge X-ray absorption fine structure (XAFS) spectra of these glasses were also the same, indicating that the average local coordination states of Mn cations were similar in the concentration range considered. The quantum efficiency of the 15 mol\%-doped MnZP glass prepared in air was lower than that of the glass prepared in Ar owing to the high absorption in the visible region of the former. It is expected that $\left(\mathrm{NH}_{4}\right)_{2} \mathrm{HPO}_{4}$, which is the starting material for $\mathrm{P}_{2} \mathrm{O}_{5}$, prevents the oxidation reaction of $\mathrm{Mn}^{2+}$ during melting in air.

\section{Introduction}

The physical properties of glass are affected by several factors. In glasses obtained by quenching of the supercooled liquid state, various metastable structures exist to form nonperiodic network structures. The non-periodic structures are the origin of the good formability of glass, which is a major advantage for large-scale industrial production. On the other hand, the redox state of the glass melt is important for tailoring the physical properties of glasses. Since glass melted in air is inherently affected by the oxygen partial pressure, the physical properties sometimes differ from those prepared in an inert atmosphere. ${ }^{(1,2)}$ The redox state affects not only the main glass components but also the tiny amount of dopants, such as activators. Our group has reported the relationship between the valence state of tin in phosphate and borate glasses and the preparation atmosphere. ${ }^{(3-5)}$ It has also been clarified that Ce cations doped in borosilicate glasses are strongly affected by the preparation conditions. ${ }^{(6-8)}$

*Corresponding author: e-mail: hirokazu.masai@aist.go.jp

https://doi.org/10.18494/SAM.2021.3326 
From the viewpoint of large-scale fabrication, examination of the effect of the preparation conditions on the physical properties is important, particularly for transition-metal-doped glasses, whose optical properties are markedly changed by a small amount of color centers. In this study, manganese (Mn) was selected as a transition metal element whose valence changes with the oxygen partial pressure during melting. $\mathrm{Mn}$ is one of the non-rare-earth luminescent centers used in phosphor applications. ${ }^{(9)} \mathrm{Mn}$ cations can exist as $\mathrm{Mn}^{4+},{ }^{(9-12)} \mathrm{Mn}^{3+}$,(13) and $\mathrm{Mn}^{2+}$ in crystals. ${ }^{(9,10,14,15)}$ The number of $\mathrm{Mn}^{2+}$-doped materials is much larger than that of materials doped with the other species, and most papers on doped glasses have reported $\mathrm{Mn}^{2+}$-doped glasses. ${ }^{(16-21)}$ So far, our group has reported on the luminescence characteristics obtained by codoping $\mathrm{ZnO}-\mathrm{P}_{2} \mathrm{O}_{5}$ glass with $\mathrm{Sn}^{2+}$ and $\mathrm{Mn}^{2+}$. ${ }^{20,21)} \mathrm{In}$ the $\mathrm{Sn}^{2+}-\mathrm{Mn}^{2+}$ co-doped glasses, energy transfer from the donor $\left(\mathrm{Sn}^{2+}\right)$ to the acceptor $\left(\mathrm{Mn}^{2+}\right)$ occurred with a high energy transfer rate. However, the effects of the preparation atmosphere on the optical and luminescence properties of $\mathrm{Mn}^{2+}$-doped phosphate glasses without the co-doping of other donor cations have not been reported. On the other hand, although Mn cations can be doped with a higher concentration than other activators, such a highly doped system has not been studied. In this study, we evaluated the thermal, optical, and luminescence properties of Mn-doped $\mathrm{ZnO}-\mathrm{P}_{2} \mathrm{O}_{5}$ glass prepared in air and $\mathrm{Ar}$ atmospheres. We also evaluated the valence state of $\mathrm{Mn}$ cations by $\mathrm{Mn} \mathrm{K}$-edge X-ray absorption fine structure (XAFS) measurement. On the basis of the obtained results, we discuss the effect of the preparation atmosphere on the optical and luminescent properties of Mn-doped phosphate glasses.

\section{Materials and Methods}

The manganese-doped $\mathrm{ZnO}-\mathrm{P}_{2} \mathrm{O}_{5}(\mathrm{MnZP})$ glasses were prepared by a conventional meltquenching method. The starting materials were $\mathrm{ZnO}, \mathrm{NH}_{4} \mathrm{H}_{2} \mathrm{PO}_{4}$, and $\mathrm{MnO}$. The molar ratio of $\mathrm{ZnO}: \mathrm{P}_{2} \mathrm{O}_{5}: \mathrm{MnO}$ was fixed as 60:40:x, and we denote the glass composition as $x \mathrm{MnZP}$ for a $\mathrm{Mn}$ concentration of $x \mathrm{~mol} \%$. These chemicals were mixed and calcined using a Pt crucible. ${ }^{(22)}$ The calcined sample was then melted in an electric furnace in $\mathrm{Ar}$ or air. The temperature and duration of glass melting were $1100{ }^{\circ} \mathrm{C}$ and $30 \mathrm{~min}$, respectively. The glass melt was poured onto a stainless-steel plate to quench it, and the obtained glass was annealed at the glass transition temperature, $T_{g}$, for $1 \mathrm{~h}$. The glasses were cut to $\sim 10 \times 10 \times 1 \mathrm{~mm}^{3}$ and mechanically polished to obtain a mirror surface.

$T_{g}$ of these glasses was measured by differential thermal analysis using a TG8120 thermal analyzer (Rigaku). The Mn K-edge XAFS spectra were measured at the BL01B1 beamline of SPring- 8 (Hyogo, Japan). The storage ring energy was operated at $8 \mathrm{GeV}$ with a typical current of $100 \mathrm{~mA}$. The measurements were performed using a Si (111) double-crystal monochromator in the transmittance or fluorescence mode using a 19-SSD detector at room temperature (RT). Pellet samples for the transmittance measurements were prepared by mixing the granular sample with boron nitride. XAFS data for $\mathrm{MnO}, \mathrm{Mn}_{2} \mathrm{O}_{3}$, and $\mathrm{MnO}_{2}$ were collected using the same conditions for reference. The corresponding analyses were performed using Athena software. ${ }^{(23)}$ The PL and PL excitation (PLE) spectra were recorded at RT using an F7000 fluorescence spectrophotometer (Hitachi High-Tech, Japan). The optical absorption spectra at RT were 
recorded using a U4150 UV-vis-NIR spectrometer (Hitachi High-Tech, Japan). The absolute quantum yields $(Q Y \mathrm{~s})$ of the glasses were measured using a Quantaurus-QY integrating sphere (Hamamatsu Photonics, Japan). The error bars were \pm 2 , which mainly originated from the samples. The emission decay at RT was measured using a Quantaurus-Tau system (Hamamatsu Photonics, Japan) using white light with a band pass filter.

\section{Results and Discussion}

First, we measured the thermal properties of the MnZP glasses prepared in air and Ar. MnO is conventionally categorized as a network-modifying oxide (NMO) according to the classification by Sun. ${ }^{(24)}$ Therefore, if the role of MnO is the same as that of other NMOs, ${ }^{(25,26)}$ $T_{g}$ should decrease monotonically with increasing Mn concentration. Figure 1 shows $T_{g}$ of the $x \mathrm{MnZP}$ glasses melted in air or Ar as a function of Mn concentration. In the MnZP glasses containing a small amount of Mn cations, $T_{g}$ decreased with increasing Mn concentration up to $2 \mathrm{~mol} \%$. However, after $5 \mathrm{~mol} \%$ addition, $T_{g}$ increased, suggesting that the network formation in these glasses was changed. If the $\mathrm{MnO}$ only acts as a network modifier without changing the network formation, $T_{g}$ will monotonically decrease. ${ }^{(26)}$ On the other hand, with increasing $\mathrm{MnO}$ fraction, i.e., decreasing $\mathrm{P}_{2} \mathrm{O}_{5}$ fraction, intermediate $\mathrm{ZnO}$ will play a role in network formation. Although it is not clear whether $\mathrm{MnO}$ can act as an intermediate group ${ }^{(24)}$ similarly to $\mathrm{ZnO},{ }^{(27)}$ it is expected that the increase in $T_{g}$ originated from the network change caused by $\mathrm{MnO}$ addition. It is notable that the effect of the preparation atmosphere on $T_{g}$ was not clear. This might be due to the valence state of the Mn cation not changing significantly. To examine this hypothesis, we next measured the Mn K-edge XANES spectra.

The preparation conditions often affect the valence state of activators in glasses. Valence changes of activators in glass, which were evaluated by XANES analysis, have been reported for several luminescent glasses. ${ }^{(3-8)}$ Figures 2(a) and 2(b) depict Mn K-edge XANES spectra of the $x \mathrm{MnZP}$ glasses melted in Ar and air, respectively. The XANES spectra of three references, $\mathrm{MnO}, \mathrm{Mn}_{2} \mathrm{O}_{3}$, and $\mathrm{MnO}_{2}$, are also shown for comparison. The shapes of the spectra are almost the same regardless of the $\mathrm{Mn}$ concentration and preparation temperature. If the absorption edge energy $E_{0}$ of $\mathrm{Mn}$ in glasses is defined as the zero of the second derivative of the absorption edge,

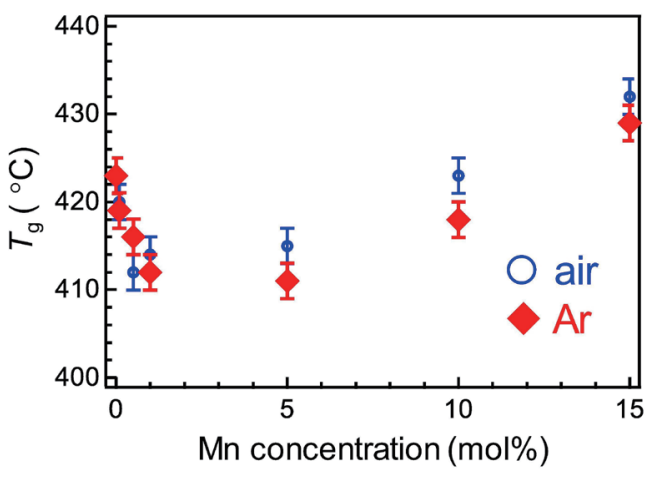

Fig. 1. (Color online) $T_{g}$ of $x \mathrm{MnZP}$ glasses prepared in air and $\mathrm{Ar}$ as a function of MnO concentration. 


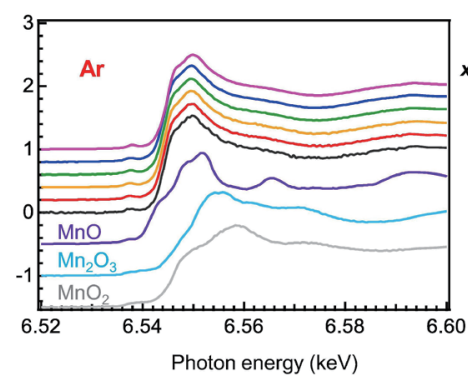

(a)

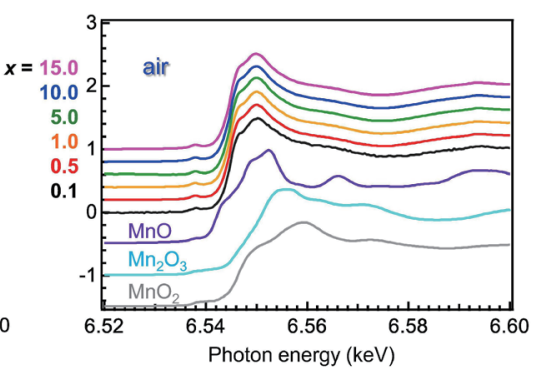

(b)

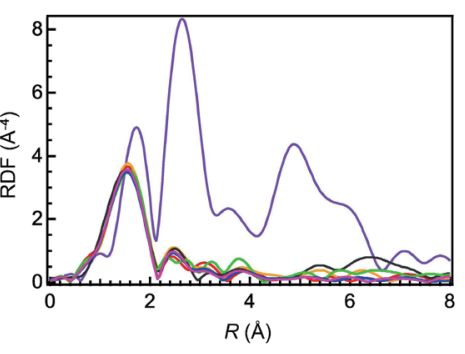

(c)

Fig. 2. (Color online) Mn K-edge XANES spectra of $x \mathrm{Mn}: \mathrm{ZP}$ glasses prepared in (a) Ar and (b) air. (c) FTs of EXAFS spectra of $x \mathrm{Mn}: \mathrm{ZP}$ glasses along with that of $\mathrm{MnO}$.

we can conclude that most of the $\mathrm{Mn}$ species exist as $\mathrm{Mn}^{2+}$ and that marked oxidation of $\mathrm{Mn}^{2+}$ to higher valence states did not occur. It has been reported that ammonium phosphate, which was the starting material used to obtain $\mathrm{P}_{2} \mathrm{O}_{5}$, affects the redox state of a glass melt, and that the reduction of the activator is preferentially induced by the residual ammonium species. ${ }^{(5)} \mathrm{In}$ other words, the oxidation of $\mathrm{Mn}^{2+}$ in the preparation of the glass melts in air was prevented by using $\left(\mathrm{NH}_{4}\right)_{2} \mathrm{HPO}_{4}$. This suggests that there is no significant difference in the XAFS spectra between the glass melted in $\mathrm{Ar}$ and the one melted in air, and that almost all the Mn species exist as $\mathrm{Mn}^{2+}$ valence states in $\mathrm{ZnO}-\mathrm{P}_{2} \mathrm{O}_{5}$ glasses melted in both air and Ar. This suggestion based on $\mathrm{Mn}$ K-edge XANES analysis is consistent with the above hypothesis based on the $T_{g}$ data of these glasses. Figure 2(c) shows the Fourier transforms (FTs) of the XAFS spectra in the extended XAFS (EXAFS) region. Both the Mn-O distance and the coordination are similar regardless of the concentration and the preparation atmosphere. The structural change suggested by the $T_{g}$ measurement was not observed. Thus, we assumed that the difference in $T_{g}$ originated from the zinc phosphate network. Considering the octahedral coordination of Mn cations in MnO crystal, it is expected that the $\mathrm{Mn}^{2+}$ sites in these glasses will be octahedral.

Although the obtained $x \mathrm{MnZP}$ glasses were transparent, the coloration increased with increasing $\mathrm{MnO}$ concentration. Figure 3 shows optical absorption spectra of the $x \mathrm{MnZP}$ glasses melted in air (dashed lines with circles) and Ar (solid lines). The coloration of the glasses is mainly due to the absorption corresponding to the ${ }^{6} \mathrm{~A}_{1}$ to ${ }^{4} \mathrm{~A}_{1 \mathrm{~g}}$ transition. ${ }^{(28,29)}$ In the case of the $0.1 \mathrm{MnZP}$ glass, although a small deviation of the absorption coefficient was observed at the onset of the absorption edge, the optical absorption coefficient of the MnZP glasses prepared in air was almost the same as those of the glasses prepared in Ar. On the other hand, a significant redshift of the absorption edge was observed in the 15MnZP glass prepared in air. Since the shape of the XAFS spectrum of the 15MnZP glass melted in Ar is almost the same as that of the $15 \mathrm{MnZP}$ glass melted in air, this drastic change owing to the Mn species was unexpected. It has been reported that manganese oxide colloids possess a broad absorption tail in the visible region. ${ }^{(30)}$ We assume that the origin of the strong absorption in the near-UV region is a type of Mn cluster whose relative concentration was too low to be detected in the K-edge Mn XANES spectrum. 


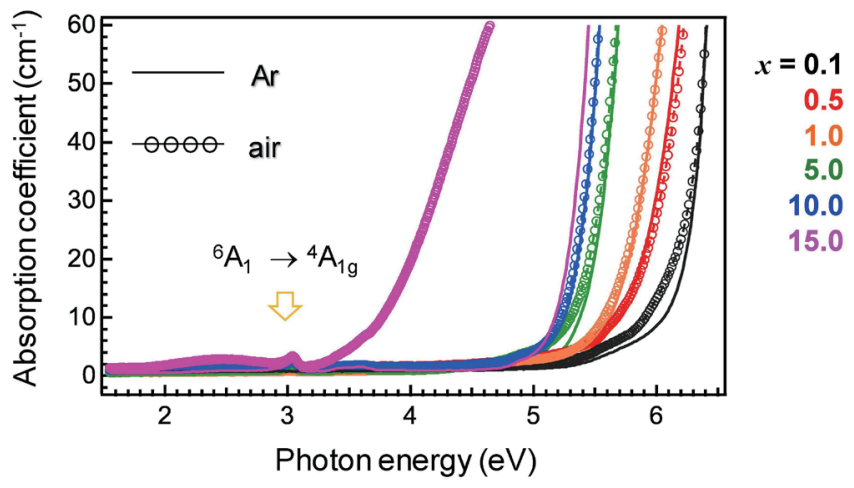

Fig. 3. (Color online) Optical absorption spectra of $x \mathrm{MnZP}$ glasses prepared in air and Ar.

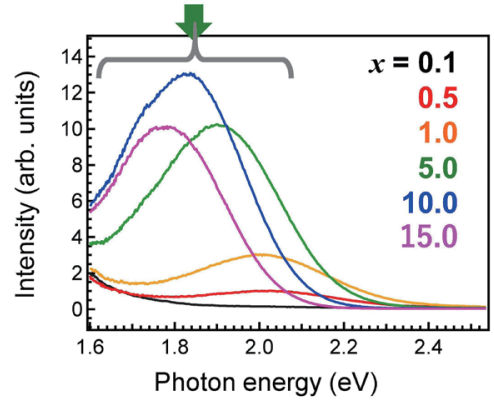

(a)

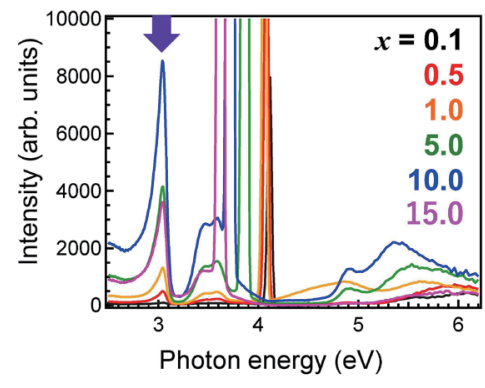

(b)

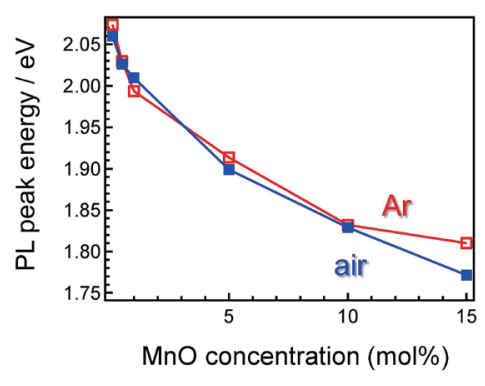

(c)

Fig. 4. (Color online) (a) PL and (b) PLE spectra of $x$ MnZP glasses prepared in air. (c) PL peak energies of $x$ MnZP glasses prepared in air and Ar.

For all chemical compositions, the emission intensity of the PL-PLE spectra of the $x$ MnZP glass melted in Ar was higher than that of the glass melted in air. Figures 4(a) and 4(b) show the PL and PLE spectra of the $x \mathrm{MnZP}$ glasses prepared in air, respectively. The PL spectra were obtained by excitation of $3.05 \mathrm{eV}(407 \mathrm{~nm})$, whereas the PLE spectra were obtained by scanning of the peak energy of the PL spectra. In the PL spectra, the emission peak energy underwent a redshift with increasing $\mathrm{Mn}$ concentration. Since the absorption band of the ${ }^{6} \mathrm{~A}_{1}-{ }^{4} \mathrm{~A}_{1 \mathrm{~g}}$ transition exists in the visible region (see Fig. 3), it is assumed that the redshift of the PL spectra was mainly due to the increase in absorption, i.e., band overlap between PL and PLE. Although the PL intensity takes a maximum at a concentration of $10 \mathrm{~mol} \%$, the intensity differences between the $5 \mathrm{MnZP}$ and $10 \mathrm{MnZP}$ glasses are not so large. Therefore, we conclude that concentration quenching occurred at $10 \mathrm{~mol} \%$ and above. To compare the dependence of the PL properties on the preparation atmosphere, the PL peaks of the MnZP glasses prepared in air and Ar as a function of $\mathrm{MnO}$ concentration are compared in Fig. 4(c). The red emission observed from these Mn-doped glasses originated from octahedral-coordinated $\mathrm{Mn}^{2+},{ }^{(9)}$ which was also suggested by the XAFS analysis. 
To investigate the emission from $\mathrm{Mn}^{2+}$ centers, we measured the PL decay curves of the glasses. Figure 5(a) shows PL decay curves of the $x$ MnZP glasses melted in Ar (solid lines) and air (open circles). The excitation energy was $\sim 400 \mathrm{~nm}$ and was filtered by a band pass filter. For all MnZP glasses, the decay curves consist of two components: a faster component (lifetime, $\tau_{1 / \mathrm{e}}^{\prime}$, of microseconds) and a slower component ( $\tau_{1 / \mathrm{e}}^{\prime \prime}$ of milliseconds). Considering the previous decay constants of $\mathrm{Mn}^{2+}$ centers in oxide crystals or oxide glasses, the decay with ms-order lifetime was due to the ${ }^{4} \mathrm{~T}_{2} \rightarrow{ }^{6} \mathrm{~A}_{1}$ radiative transition, whose decay constant decreases with increasing $\mathrm{MnO}$ concentration. The decay constant is comparable to that previously reported in Refs. 9 and 31. However, a considerable difference between the decay curves of the Ar-prepared and air-prepared samples was observed for the $15 \mathrm{MnZP}$ glasses. It is expected that this difference was due to strong absorption in the visible region for the 15MnZP glass prepared in air.

Figure 5(b) shows $\mathrm{QE}$ values of the $x \mathrm{MnZP}$ glasses prepared in air and Ar as a function of Mn concentration. For the MnZP glasses with Mn concentration below $10 \mathrm{~mol} \%$, the QE values of the MnZP glasses prepared in air are comparable to those of the glasses prepared in Ar. The QE values of these glasses are approximately $60 \%$. It is notable that the maximum QE values of the MnZP glasses are the same for both preparation atmospheres. It is expected that residual ammonium groups after calcination affected the redox state of the glass melt to induce a reducing condition. The reducing condition is the main factor preventing the oxidation reaction of $\mathrm{Mn}^{2+}$. This reducing condition resulting from the ammonium phosphate used as a starting material has also been reported for Sn-doped phosphate glass. ${ }^{(32)} \mathrm{In}$ the case of $\mathrm{Sn}^{2+}$, it has been found that most of the $\mathrm{Sn}^{2+}$ was oxidized during melting even when using ammonium phosphate. Therefore, as suggested from the redox reaction, Mn oxidation is more greatly inhibited by ammonium phosphate than Sn oxidation during melting. In contrast, large degradation of the QE value was observed in the $15 \mathrm{MnZP}$ glass melted in air. We assume that the origin of this decrease was the strong absorption of $\mathrm{Mn}^{2+}$ in the visible region, which was also the origin of the faster decay shown in Fig. 5(a).

Here, we consider the optical basicity proposed by Duffy and Ingram. ${ }^{(33)}$ Since MnO was added as an additive, the basicity was changed, especially in the more highly MnO-doped samples. Using the optical basicity of each metal oxide, ${ }^{(34)}$ we calculated the $\Lambda$ value of $10 \mathrm{MnZP}$

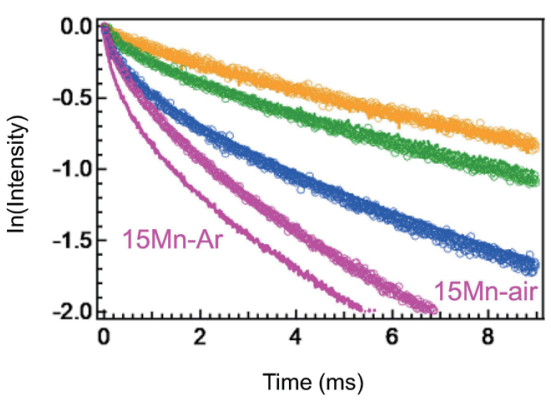

(a)

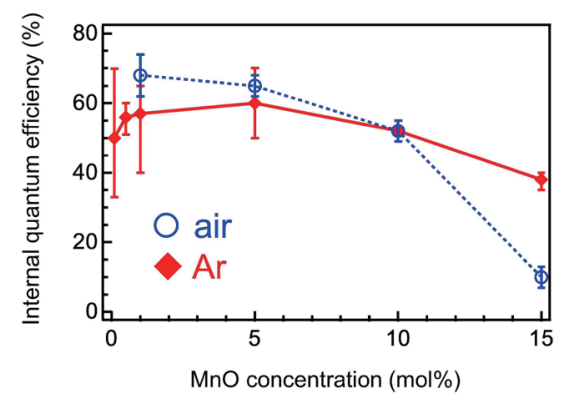

(b)

Fig. 5. (Color online) (a) PL decay curves of $x \mathrm{MnZP}$ glasses prepared in Ar and air. (b) Internal QE values of $x \mathrm{MnZP}$ glasses as a function of $\mathrm{MnO}$ concentration. 


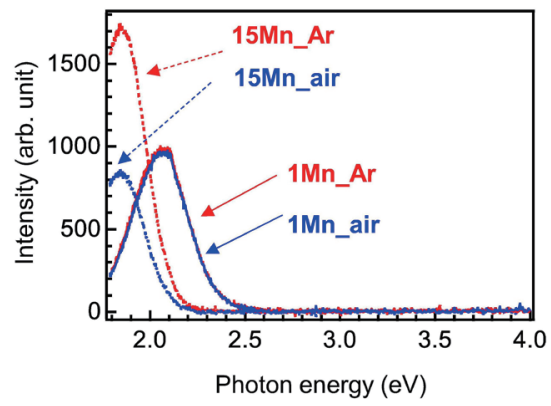

(a)

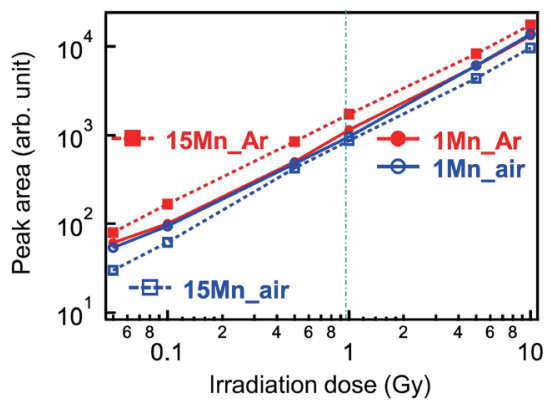

(b)

Fig. 6. (Color online) (a) X-ray-induced scintillation spectra of 1MnZP and 15MnZP glasses prepared in air and Ar. These spectra were obtained after X-ray irradiation of $1 \mathrm{~Gy}$. (b) Scintillation peak areas of 1MnZP and 15MnZP glasses prepared in air and Ar. These data are plotted as a function of $\mathrm{MnO}$ concentration.

glass as 0.802 , which is approximately $14 \%$ higher than that of the Mn-free ZP glass (0.702). Thus, the $\Lambda$ value suggests that a higher valence state of $\mathrm{Mn}$ is more preferentially formed upon the addition of $\mathrm{MnO}$.

Finally, we measured the X-ray-induced scintillation spectra of the MnZP glasses. Figure 6(a) shows the X-ray-induced scintillation spectra of the 1MnZP and 15MnZP glasses prepared in air and Ar, whose spectra were obtained after X-ray irradiation of $1 \mathrm{~Gy}$. In the case of the MnZP glasses with low Mn concentrations, the scintillation intensities were almost the same regardless of the preparation atmosphere. In contrast, a significant difference was observed between the $15 \mathrm{MnZP}$ glasses. Although the maximum scintillation intensity was observed in both 10MnZP glasses, a large decrease in the scintillation intensity was observed in the $15 \mathrm{MnZP}$ glass prepared in air. These tendencies are similar to the various PL properties.

Figure 6(b) shows the scintillation peak areas of the 1MnZP and 15MnZP glasses prepared in air and $\mathrm{Ar}$ as a function of $\mathrm{MnO}$ concentration. In the case of $1 \mathrm{MnZP}$ glass, there is no marked difference between the peak areas of the air- and Ar-prepared samples. These scintillation data are consistent with the PL data, which confirms that the absorption property of these glasses in the visible region governs all their luminescence properties.

\section{Conclusions}

We have examined the optical and luminescence properties of MnZP zinc phosphate glasses prepared in air and Ar. The Mn-K edge XANES spectra of the glasses suggest that most of the $\mathrm{Mn}$ species exist as $\mathrm{Mn}^{2+}$ states regardless of the preparation atmosphere. The luminescence and absorption properties appeared to be similar in the MnZP glasses with a $\mathrm{Mn}^{2+}$ concentration of $10 \mathrm{~mol} \%$ or below. In contrast, marked differences in the absorption spectrum, decay constant, and quantum efficiency were observed in the $15 \mathrm{~mol} \%$-doped $\mathrm{Mn}^{2+} \mathrm{ZP}$ glasses. Considering the optical basicity of the host glass, it is expected that Mn cations with the valence state higher than divalent preferentially exist in Mn-rich glasses, which is one of the reasons for the coloration in the glasses doped with higher concentrations of Mn. 


\section{Acknowledgments}

This work was partially supported by the Japan Society for the Promotion of Science Grantsin-Aid for Scientific Research (B) (Number 18H01714) and for Challenging Research (Exploratory) (Number 19K22072). The synchrotron radiation experiments were performed at the BL01B1 beamline of SPring-8 with the approval of the Japan Synchrotron Radiation Research Institute (JASRI) (Proposal No. 2018B1239). This work was partially supported by the Cooperative Research Project of the Research Institute of Electronics, Shizuoka University.

\section{References}

1 F. Farges, C. W. Ponader, G. Calas, and G. E. Brown: Geochim. Cosmochim. Acta 56 (1992) 4205.

2 G. K. Marasinghe, M. Karabulut, C. S. Ray, D. E. Day, M. G. Shumsky, W. B. Yelon, C. H. Booth, P. G. Allen, and D. K. Shuh: J. Non-Cryst. Solids 222 (1997)144.

3 H. Masai, T. Ina, and K. Mibu: Sci. Rep. 8 (2018) 415.

4 H. Masai, Y. Suzuki, T. Yanagida, and K. Mibu: Bull. Chem. Soc. Jpn. 88 (2015) 1047.

5 H. Masai, T. Tanimoto, S. Okumura, K. Teramura, S. Matsumoto, T. Yanagida, Y. Tokuda, and T. Yoko: J. Mater. Chem. C. 2 (2014) 2137.

6 H. Masai and T. Yanagida: Opt. Mater. Express 5 (2015) 1851.

7 H. Masai, G. Okada, A. Torimoto, T. Usui, N. Kawaguchi, and T. Yanagida: Sci. Rep. 8 (2018) 623.

8 H. Masai, G. Okada, T. Ina, N. Kawaguchi, and T. Yanagida: J. Lumin. 207 (2019) 316.

9 M. Tamatani: Phosphor Handbook 2nd Edition, W. M. Yen, S. Shionoya, and H. Yamamoto, Eds. (CRC Press, Boca Raton, USA, 2007).

10 Q. Zhou, L. Dolgov, A. M. Srivastava, L. Zhou, Z. Wang, J. Shi, M. D. Dramićanin, M. G. Brikef, and M. Wu: J. Mater. Chem. C. 6 (2018) 2652.

11 G. Kemeny and C. H. Haake: J. Chem. Phys. 33 (1960) 783.

12 B. Wang, H. Lin, J. Xu, H. Chen, and Y. Wang: ACS Appl. Mater. Interfaces 6 (2014) 22905.

13 S. Kück, S. Hartung, S. Hurling, K. Petermann, and G. Huber: Phys. Rev. B 57 (1997) 2203.

14 S. Ye, F. Xiao, Y. X. Pan, Y. Y. Ma, and Q. Y. Zhang: Mat. Sci. Eng. R 71 (2010) 1.

15 P. F. Smet, A. B. Parmentier, and D. Poelman: J. Electrochem. Soc. 158 (2011) R37.

16 R. Reisfeld, A. Kisilev, and C. K. Jorgensen: Chem. Phys. Lett. 111 (1984) 19.

17 P. I. Paulose, G. Jose, V. Thomas, N. V. Unnikrishnan, and M. K. R. Warrier: J. Phys. Chem. Solids 64 (2003) 841.

18 D. Ehrt: J. Non-Cryst. Solids 348 (2004) 22.

19 U. Caldino, J. L. Hernandez-Pozos, C. Flores, A. Speghini, and M. Bettinelli: J. Phys. Condens. Matter 17 (2005) 7297.

20 H. Masai, T. Fujiwara, S. Matsumoto, Y. Takahashi, K, Iwasaki, Y. Tokuda, and T. Yoko: Opt. Lett. 36 (2011) 2868.

21 H. Masai, Y. Hino, T. Yanagida, Y. Fujimoto, and Y. Tokuda: Opt. Mater. Express 5 (2015) 617.

22 H. Masai, T. Tanimoto, T. Fujiwara, S. Matsumoto, Y. Takahashi, Y. Tokuda, and T. Yoko: J. Non-Cryst. Solids 358 (2012) 265.

23 B. Ravel and M. Newville: J. Synchrotron Radiat. 12 (2005) 537.

24 K. H. Sun: J. Am. Ceram. Soc. 30 (1947) 277.

25 R. Knoche, D. B. Dingwell, F. A. Seifert, and S. L. Webb: Chem. Geology 116 (1994) 1.

26 P. Richet and Y. Bottinga: Rev. Geophys. 24 (1986) 1.

27 Y. Onodera, S. Kohara, H. Masai, A. Koreeda, S. Okamura, and T. Ohkubo: Nat. Commun. 8 (2017) 15449.

28 K. Bingham and S. Parke: Phys. Chem. Glasses 6 (1965) 224.

29 A. Srinivasa Rao, B. Sreedhar, J. Lakshmana Rao, and S. V. J. Lakshman: J. Non-Crystal. Solids 144 (1992) 169.

30 S. L. Brock, M. Sanabria, S. L. Suib, V. Urban, P. Thiyagarajan, and D. I. Potter: J. Phys. Chem. B 103 (1999) 7416.

31 H. Masai, Y. Hino, T. Yanagida, and Y. Fujimoto: Opt. Mater. 42 (2015) 381.

32 H. Masai, Y. Takahashi, T. Fujiwara, S. Matsumoto, and T. Yoko: Appl. Phys. Express 3 (2010) 082102.

33 J. A. Duffy and M. D. Ingram: J. Am. Chem. Soc. 93 (1971) 6448.

34 J. A. Duffy: Geochim. Cosmochim. Acta 57 (1993) 3961. 